\title{
Disparity in oesophageal cancer management in South Africa: a comparison between two tertiary centres with special focus on the palliation of dysphagia
}

\author{
D Nel, ${ }^{1}$ M Omar, ${ }^{2}$ G Chinnery, ${ }^{3}$ E Jonas ${ }^{4}$ \\ ${ }^{1}$ Division of General Surgery, Groote Schuur Hospital, Cape Town, South Africa \\ ${ }^{2}$ University of Cape Town, South Africa \\ ${ }^{3}$ Upper GI surgery, Surgical Gastroenterology Unit, Division of General Surgery, Groote Schuur Hospital, Cape Town, \\ South Africa \\ ${ }^{4}$ Surgical Gastroenterology Unit, Division of General Surgery, Groote Schuur Hospital, Cape Town, South Africa
}

Corresponding author: Daniel Nel(danielnel87@gmail.com)

\begin{abstract}
Background: For most patients with oesophageal cancer worldwide, palliation of dysphagia is the goal which is most commonly achieved with self-expanding metal stents (SEMS). The aim of this study was to assess the profile and management of oesophageal cancer patients at Frere Hospital in the Eastern Cape, and compare this to a similar cohort from Groote Schuur Hospital (GSH) in the Western Cape Province.

Methods: This study is a retrospective comparative cohort which reviewed all patients diagnosed with oesophageal cancer by the Frere Hospital and GSH endoscopy units from January to December 2015. Independent prospective electronic databases for the two hospitals were merged for comparative analysis.

Results: During the study period, 346 and 108 patients were diagnosed with oesophageal cancer at Frere Hospital and GSH respectively. The rate of curative intended intervention was similarly low, with $3 \%$ of cases at Frere Hospital undergoing oesophagectomy or definitive radiotherapy as compared to $5 \%$ at GSH ( $\mathrm{p}=0.48)$. In terms of palliation, significantly more patients received palliative oncological therapy at GSH as compared to Frere Hospital $(21 \%$ vs $8 \%$, p $<0.001)$. At Frere Hospital, 281 patients (81\%) were treated primarily with serial dilatations. At GSH, 9 patients received a single dilatation, all as a bridge to radiotherapy or stenting. At Frere Hospital, 28 patients (8\%) were stented, as compared to GHS where 69 patients $(64 \%)$ were managed with a stent $(\mathrm{p}<0.001)$.

Conclusion: This study shows significant differences in the oncological and endoscopic palliation of patients between the two institutions, highlighting a gross disparity in healthcare provision between them. The reasons for these disparities should be investigated and equipoise addressed by national health policy makers.
\end{abstract}

S Afr J Surg 2019;57(2)

http://dx.doi.org/10.17159/2078-5151/2019/v57n2a2842

\section{Introduction}

Global epidemiological studies have shown that oesophageal cancer is both more common and deadly in the developing world, where it ranks eighth for cancer incidence and fifth for cancer mortality. ${ }^{1-3}$ Whereas adenocarcinoma is more prevalent in Western societies, squamous cancer of the oesophagus predominates in the developing world. ${ }^{3}$ South Africa has a high incidence of oesophageal cancer, in particular in the Eastern Cape where epidemiologists in the 1950s discovered an especially high incidence and it remains the cancer with the highest incidence and mortality rate in the region. - $^{4}$
Despite improvement in treatment outcomes in the last few decades, the prognosis of oesophageal cancer remains poor, with an overall 5-year survival of $14 \% .{ }^{9,10}$ In a first world setting, $40 \%$ of patients present with metastatic disease and less than half of patients will be candidates for potential curative resection. ${ }^{9}$ In Africa, patients have a greater delay in presentation, present at a more advanced stage, are less often candidates for resection, and have a poorer overall outcome. ${ }^{11-17}$ For most patients, cure is not an option and best supportive care (BSC) with palliation of dysphagia is the goal. ${ }^{18}$ Dysphagia relief can be achieved with placement of self-expanding metal stents (SEMS), radiotherapy (brachytherapy or external beam radiotherapy (EBRT)) 
or oesophageal dilatation. SEMS are the most commonly used method and have been shown to offer rapid, safe and effective relief of dysphagia with low procedure-related morbidity and mortality rates. ${ }^{19-24}$ Brachytherapy and EBRT, although effective, have a delay in symptom relief, making it unsuitable in patients with $<3$ estimated survival months. ${ }^{25-29}$ Oesophageal dilatation is easy and cheap, with a complication rate (mainly perforation) of 2.5-10\%. Unfortunately, the effect is short lived and necessitates a serial dilatation policy. ${ }^{30-33}$ Older guidelines have recommended dilatation alone for patients with an expected life span of less than 4 weeks, but more recent guidelines recommend SEMS as primary intervention, reserving dilatation only for the management of post-radiotherapy strictures and very high lesions that are not stentable. ${ }^{34,35}$

South Africa remains a country with great inequality and disparity. ${ }^{36,37}$ The Eastern Cape is a poor province with a population of 6.5 million and an unemployment rate of $37 \%$, the highest in South Africa. ${ }^{4}$ The public health sector in the Eastern Cape province is indeed one of the areas hit hardest by lack of funds and infrastructure. ${ }^{38}$ The aim of this study was to compare the management of patients with oesophageal cancer at two teaching hospitals, Frere Hospital in East London and Groote Schuur Hospital in Cape Town, with special reference to palliative treatment of dysphagia.

\section{Methods}

Patients who were diagnosed with oesophageal cancer at the endoscopy units at Frere Hospital and GSH from January 2015 to December 2015 were included in the study. At GSH, patient details were retrieved from a prospectively maintained Research Electronic Data Capture (REDCap) based institutional database for patients with Upper Gastrointestinal Cancer, whereas at Frere Hospital patients were prospectively captured in an Excel spreadsheet. Demographic and clinical data captured are shown in Table 1. The criteria for diagnosing oesophageal cancer were similar for the two units: the diagnosis was based on the endoscopic picture of an obvious exophytic/ulcerative tumour in the oesophagus. The diagnosis was confirmed with biopsy unless the patient had a very obvious lesion and was deemed completely unfit for any oncological intervention. Endoscopic procedures were performed under conscious sedation at both facilities. Endoscopic interventions (dilatation with serial SavaryGilliard dilators and SEMS placement) were performed using a Seldinger guidewire technique at both hospitals. At GSH the use of fluoroscopy for guidance of endoscopic intervention was standard, whereas at Frere Hospital interventions were performed without fluoroscopy.

There were, however, notable differences in the patient assessment and referral algorithms, the availability of treatment options and the institutional policies regarding treatment allocation. At GSH, all patients with an Eastern Cooperative Oncology Group (ECOG) performance status $\leq 3$ were referred to a dedicated multidisciplinary team (MDT) conference for assessment and treatment planning.
All treatment modalities were available and patients were allocated to a treatment according to currently applied international guidelines. Specifically, in patients where palliative endoscopic intervention of dysphagia was recommended, SEMS placement was the preferred method, with dilatation only performed as a bridge to stenting or where there was a contraindication for SEMS. Adjunctive EBRT was offered to those patients who were already stented with an ECOG status of $\leq 3$ and an expected survival of at least 3 months. Palliative care facilities for terminal care of patients were available.

At Frere, patients considered fit for surgery by the endoscopist where referred to the local surgical unit for staging, and then referred to the nearest thoracic surgery unit in Port Elizabeth (300 km away) if curative-intended intervention was considered possible. Patients considered fit for oncological treatment by the endoscopist were referred to the local oncology department. Patients considered not fit for oncological therapy were managed primarily through the endoscopy unit. With limited availability of SEMS, endoscopic treatment of palliation was monthly serial dilatation of the tumour with SEMS being reserved for patients with a tracheooesophageal fistula (TOF) or where a perforation occurred during dilatation. There were no palliative facilities available for patients for terminal care.

\section{Statistical analysis}

Statistical analysis was performed with IBM SPSS Statistics version 25. Numerical variables were assessed for normality and subsequently analysed by appropriate parametric and nonparametric tests. Categorical variables were analyzed by the Chi-squared test. Unless otherwise indicated, a twotail test hypothesis was used with 0.05 as discriminator for rejection of the null-hypothesis.

\section{Results}

During 2015, 346 and 108 patients were diagnosed with oesophageal cancer at Frere Hospital and GSH respectively. The demographic and clinical parameters of patients presenting to the two units are shown in Table 1. Notable were the long intervals between symptom onset and diagnosis, median 3 (IQR 1-4) months for Frere Hospital patients and 4 (IQR 3-6) for GSH patients $(\mathrm{p}<0.001)$. At presentation, dysphagia was present in $86 \%$ and $82 \%$, and loss of weight in $43 \%$ and $69 \%$ of patients presenting to Frere Hospital and GSH respectively.

The endoscopic tumour characteristics of the two populations were comparable. In $76 \%$ of cases diagnosed at Frere hospital, a biopsy was taken for histological confirmation, compared to $86 \%$ at GSH. There were significantly more patients with an adenocarcinoma at GSH, with $12 \%$ of biopsies confirming this result as compared to $3 \%$ of cases at Frere Hospital $(p<0.001)$. Staging CT was performed in 11 patients $(3 \%)$ at Frere Hospital compared to 27 patients $(25 \%)$ at $\mathrm{GSH}(\mathrm{p}<0.001)$. 


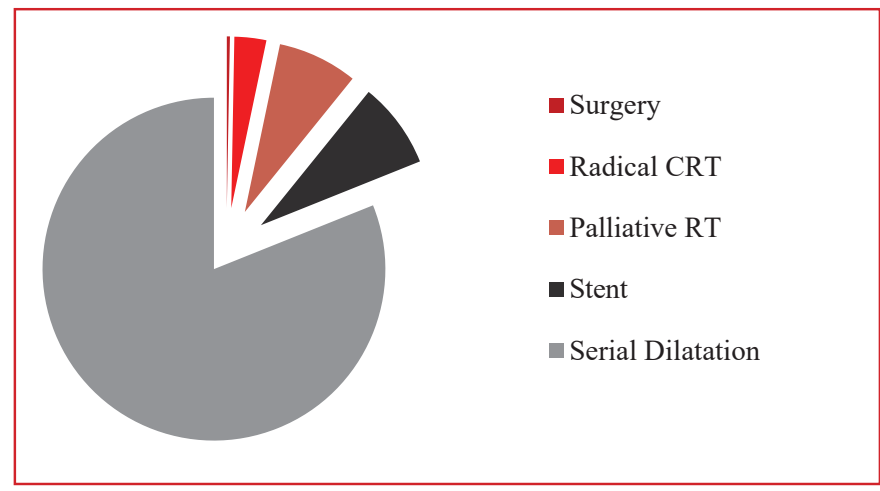

Figure 1a. Primary treatment modality at Frere Hospital

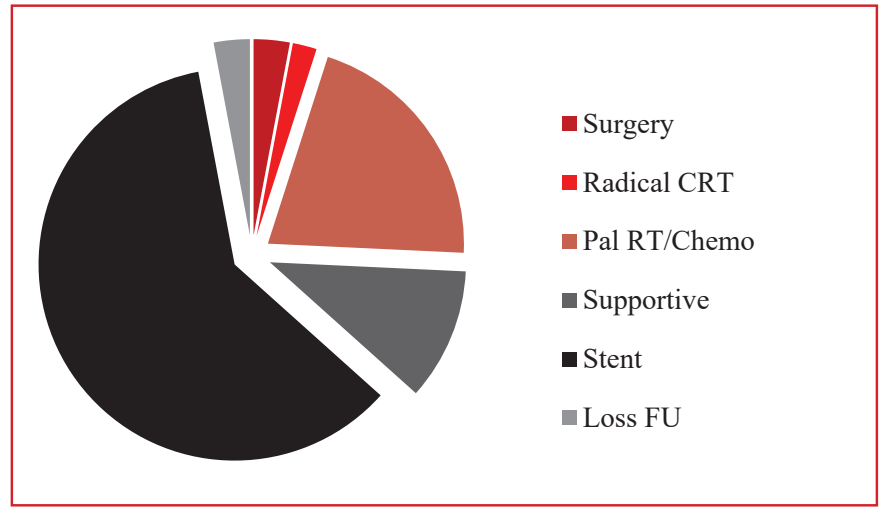

Figure 1b. Primary treatment modality at GSH

The management of patients is summarised in Table 2 and shown in Figure 1. At Frere Hospital, 15\% of patients were referred to the Oncology unit for assessment, whereas at GSH $78 \%$ of patients were discussed in the MDT conference $(\mathrm{p}<0.001)$. At Frere Hospital, 3 patients were referred for resection of which 2 refused surgery and 1 underwent oesophagectomy. At GSH, 3 patients underwent oesophagectomy. Definitive chemoradiotherapy was given in $3 \%$ and $2 \%$ of patients, and $8 \%$ and $21 \%$ of patients underwent palliative oncological treatment at Frere Hospital and GSH respectively. In addition to palliative radiotherapy alone, $27 \%$ of patients at GSH were given adjunctive radiotherapy after initial SEMS insertion.

At Frere Hospital, 281 patients (81\%) were treated with intended serial dilatations, with the number of actual dilatations performed per person shown in Figure 2. Notably, more than $50 \%$ of patients selected for serial dilataion underwent two or more dilatations, with 47 patients returning 4 or more times, and one patient who had up to eleven dilatations. The median interval between dilatation sessions was 4 weeks (range 1-16 weeks). The failure rate for dilatation was $5 \%$, while the perforation rate was $3 \%$. At GSH, 9 patients received a single dilatation, but all of these were as a bridging intervention to palliative radiotherapy or stenting. No patients were allocated to serial dilatation.

At Frere, 28 patients $(8 \%)$ were stented. The most common indication for stent placement was the presence of a TOF $(\mathrm{n}=15)$, followed by iatrogenic perforation $(\mathrm{n}=7)$ and luminal obstruction $(n=5)$. At GSH, 69 patients $(64 \%)$ were stented, of whom 61 were for luminal obstruction only, four were for tracheo-oesophageal fistulae and in three patients it was as a bridge to surgery.

\section{Discussion}

Most patients with oesophageal cancer treated at state health facilities in South Africa present with advanced disease with curative-intended intervention applicable in less than $20 \%{ }^{17,39,40}$ The majority of patients require palliative measures aimed at the alleviation of symptoms, predominantly dysphagia and pain. This study shows significant differences in management of oesophageal cancer between the two study centres. Of concern are the discrepancies in the oncological and endoscopic palliation of patients available at the two centres.

Delay from the onset of symptoms to contact with an appropriate level health care facility is a major factor contributing to most patients presenting with advanced disease. ${ }^{39}$ The lengthy time intervals between onset of symptoms and seeking medical attention observed in

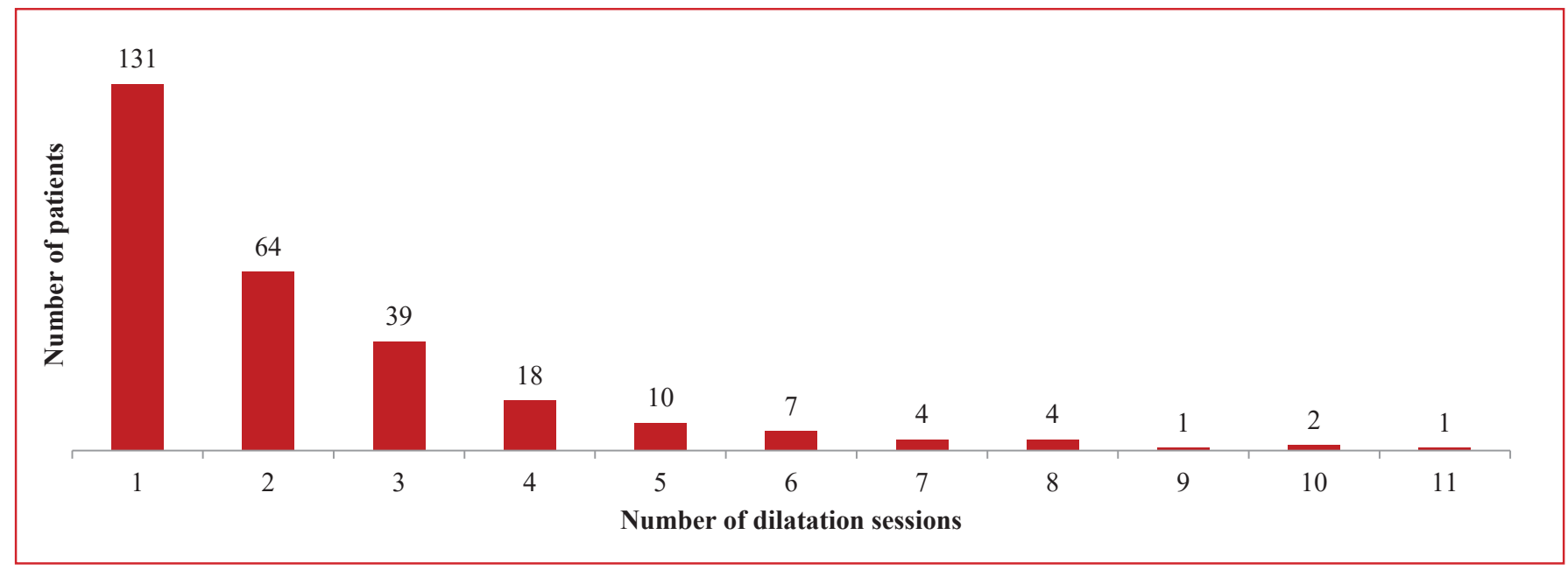

Figure 2. Number of dilatations per patient at Frere Hospital 
Table 1. Demographic, clinical and endoscopic parameters of patients

Groote Schuur Hospital

$\mathrm{n}=108$

Frere Hospital

$\mathrm{n}=346$

p-value

Demographic parameters

\begin{tabular}{|c|c|c|c|}
\hline Age (median; range) & $60(34-82)$ & $64(35-95)$ & 0.01 \\
\hline Male/female (\%) & $47 / 53$ & $47 / 53$ & 0.97 \\
\hline \multicolumn{4}{|l|}{ Clinical parameters } \\
\hline $\begin{array}{l}\text { Duration of symptoms in months (median; } \\
\text { IQR) }\end{array}$ & $4(3-6)$ & $3(1-4)$ & $<0.001$ \\
\hline Dysphagia (\%) & 82 & 86 & 0.17 \\
\hline History of weight loss (\%) & 69 & 43 & $<0.001$ \\
\hline \multicolumn{4}{|l|}{ Endoscopic parameters } \\
\hline Tumour length (median; range) & $6(2-10)$ & $6(1-15)$ & 0.52 \\
\hline Tumour position & 85 & 340 & \\
\hline Cervical (\%) & 4 & 1 & 0.19 \\
\hline Upper thoracic (\%) & 12 & 14 & 0.67 \\
\hline Middle thoracic (\%) & 54 & 59 & 0.32 \\
\hline Lower thoracic $(\%)$ & 30 & 26 & 0.87 \\
\hline Tracheo-oesophageal fistula (\%) & 6 & 5 & 0.40 \\
\hline \multicolumn{4}{|l|}{ Pathological verification } \\
\hline $\mathrm{n}(\%)$ & $88(81 \%)$ & $245(71 \%)$ & 0.03 \\
\hline Squamous carcinoma (\%) & 88 & 97 & $<0.001$ \\
\hline Adenocarcinoma (\%) & 12 & 3 & $<0.001$ \\
\hline \multicolumn{4}{|l|}{ Staging workup } \\
\hline CT staging (n (\%)) & $27(25 \%)$ & $11(3 \%)$ & $<0.001$ \\
\hline
\end{tabular}

Table 2. Treatment at the two hospitals

\begin{tabular}{|c|c|c|c|}
\hline & Groote Schuur Hospital & Frere Hospital & \\
\hline & $\mathrm{n}=108$ & $n=346$ & $\mathrm{p}$-value \\
\hline MDT assessment (n (\%)) & $84(78 \%)$ & $52(15 \%)$ & $<0.001$ \\
\hline Curative-intended intervention ( $\mathrm{n}(\%)$ ) & $5(5 \%)$ & $11(3 \%)$ & 0.48 \\
\hline Oesophagus resection (n (\%)) & $3(3 \%)$ & $1(0.3 \%)$ & 0.09 \\
\hline Chemo-radiotherapy (n (\%)) & $2(2 \%)$ & $10(3 \%)$ & 0.85 \\
\hline Palliative oncologic treatment (n (\%)) & $23(21 \%)$ & $28(8 \%)$ & $<0.001$ \\
\hline Chemotherapy (n (\%)) & $2(2 \%)$ & 0 & \\
\hline $\operatorname{EBRT}(\mathrm{n}(\%))$ & $21(19 \%)$ & $28(8 \%)$ & $<0.001$ \\
\hline EBRTadjunctive to SEMS & $30(27 \%)$ & 0 & \\
\hline Endoscopic treatment (n (\%)) & $69(64 \%)$ & $308(89 \%)$ & $<0.001$ \\
\hline Serial dilatation $(\mathrm{n}(\%))$ & $0(0 \%)$ & $281(81 \%)$ & \\
\hline SEMS (n (\%)) & $69(64 \%)$ & $28(8 \%)$ & $<0.001$ \\
\hline
\end{tabular}

MDT multidisciplinary team; SEMS self-expanding metal stent; EBRT external beam radiotherapy 
this study is in keeping with results of Govender et al where combinations of delay in seeking medical attention, inaccessibility of health care and delays in assessment and treatment resulted in average times of symptom-onset to treatment of 7 months. Even though the proportion of patients that eventually underwent curative-intended intervention was similarly low between the two centres, it is nonetheless of concern that only $3 \%$ of patients at Frere Hospital were even investigated for this possibility by having a staging CT performed. This rate is significantly lower when compared to the GSH cohort and indeed any described in the literature, including studies from similarly resourced settings in South Africa and other African countries. ${ }^{11-15,17}$ Furthermore as opposed to GSH where, in line with international consensus guidelines $76 \%$ of patients were assessed in a MDT setting, there was no formal MDT at Frere Hospital and only 15\% of patients were referred at the discretion of the endoscopist. ${ }^{17,18,35}$ The decision to do a staging CT and refer to the oncology unit is based on a subjective assessment of patient fitness by the diagnosing endoscopist, and thus the lack of a standardised and objective assessment protocol may have contributed to fewer patients being offered and receiving oncological therapy.

Of the palliative strategies available, SEMS is the most commonly used as it offers rapid, safe and effective relief of dysphagia. ${ }^{19-24}$ Despite enough skill and eagerness to use SEMS by the endoscopy staff at Frere Hospital, the limited availability of SEMS has forced clinicians to apply a very selective stenting policy, resorting to serial dilatation as the primary dysphagia directed modality. Besides being associated with rapid recurrence of symptoms, this strategy is not ideal for several additional reasons, particularly so in the Frere Hospital context. ${ }^{30-33}$ First, the significant burden serial dilatations place on the unit means longer endoscopy waiting lists. Second, many patients from rural areas are extremely poor and the long distance to travel to hospital for monthly dilatation is a significant challenge and financial burden. Third, although inexpensive for a single session, repeated dilatation sessions become increasingly expensive to the health system as well as to the patient. Although the once off cost of a SEMS compared to single dilatation is greater, this perceived cost advantage will be eroded by the cumulative costs involved in repeated dilatation sessions. The fact that more than $50 \%$ of patients underwent multiple dilatations, with 47 receiving 4 or more dilatations and some patients undergoing up to 11 dilatations, underscores the ineffectiveness of the serial dilatation strategy in this setting.

As a retrospective comparative study, the study has several weaknesses. Patients were not staged according to the TNM staging system as the majority of patients did not undergo a staging CT. The perceived superior outcome of SEMS as opposed to serial dilatations, although published earlier, was not investigated with follow-up and, more specifically, quality of life (QOL) assessment in the patient cohorts. Furthermore, a health-economic assessment and comparison of the cost of SEMS and serial dilatation, including the potential financial implications for patients, is needed.
Despite the weaknesses, the paper addresses an important aspect, namely ongoing inequalities in the delivery of healthcare in the state service in South Africa. It is particularly disturbing that this inequality is present and needs to be highlighted in patients with advanced presentation of a disease with a dismal prognosis and debilitating symptoms. The results of this article can be used as benchmark to assess the effect and success of any remedial measures to rectify this significant disparity in healthcare provision to patients with oesophageal cancer in South Africa.

\section{Conclusion}

This study highlights that in a hospital with a high prevalence of oesophageal cancer, facilities for the appropriate management of patients are totally inadequate when compared to another referral hospital in a different province. Access to the most effective form of palliation (SEMS) needs to be addressed as a matter of urgency. Using modern technology to establish an MDT, where patients can be assessed for appropriate therapy in a standardised manner, should be the foundation step for research to determine the optimal palliative treatment and integration of care pathways.

\section{Ethics approval}

The registry from which patients were included from GSH as well as the specific research reported on was approved by the Human Research Ethics Committee (HREC) of the University of Cape Town. The study was also approved by the Ethics Review Board of Frere Hospital.

The authors have no conflicting interests to declare.

\section{REFERENCES}

1. Global Burden of Disease Cancer Collaboration. The global burden of cancer 2013. JAMA Oncology. 2015 Jul 1;1(4):505. PMID: 26181261

2. Ferlay J, Soerjomataram I, Dikshit R, Eser S, Mathers C, Rebelo $\mathrm{M}$, et al. Cancer incidence and mortality worldwide: sources, methods and major patterns in GLOBOCAN 2012. Int J Cancer. 2015 Mar 1;136(5). Available from: http://globocan. iarc.fr PMID: 25220842

3. Melhado RE, Alderson D, Tucker O. The Changing Face of Esophageal Cancer. Cancers [Internet]. MDPI AG; 2010 Jun 28;2(3):1379-404. Available from: http://dx.doi.org/10.3390/ cancers2031379 PMID:24281163

4. Somdyala NIM, Bradshaw D, GelderblomWCA. Cancer incidence in selected municipalities of the Eastern Cape Province, 2003-2007. Eastern Cape Province Cancer Registry Technical Report. Cape Town: South African Medical Research Council, 2013. ISBN: 978-1-920618-10-0.

5. Rose EF, McGlashan ND. The spatial distribution of oesophageal carcinoma in the Transkei, South Africa. Br J Cancer. Springer Nature; 1975 Feb;31(2):197-206. Available from: http://dx.doi.org/10.1038/bjc.1975.26 PMID: 1164469

6. Jaskiewicz FE. Oesophageal and other main cancer patterns in four districts of Transkei, 1981-1984. S Afr Med J. 1987 Jul 1;72(1):27-30. PMID: 3603288

7. Somdyala NI, Bradshaw D, Gelderblom WC, Parkin DM. Cancer incidence in a rural population of South Africa, 19982002. Int J Cancer. Wiley; 2010 Feb 16;127(10):2420-9. Available from: http://dx.doi.org/10.1002/ijc.25246 PMID: 20162610

8. Somdyala NIM, Parkin DM, Sithole N, Bradshaw D. Trends in 
cancer incidence in rural Eastern Cape Province; South Africa, 1998-2012. Int J Cancer. Wiley; 2014 Oct 3;136(5):E470-E474. Available from: http://dx.doi.org/10.1002/ijc.29224 PMID: 25236502

9. Dubecz A, Gall I, Solymosi N, Schweigert M, Peters JH, Feith $\mathrm{M}$, et al. Temporal Trends in Long-Term Survival and Cure Rates in Esophageal Cancer: A SEER Database Analysis. J Thorac Oncol. 2012 Feb;7(2):443-7. Available from: http:/ dx.doi.org/10.1097/jto.0b013e3182397751 PMID: 22173700

10. Rustgi AK, El-Serag HB. Esophageal Carcinoma. Ingelfinger JR, ed.. N Engl J Med (NEJM/MMS). 2014 Dec 25;371(26):2499509. Available from: http://dx.doi.org/10.1056/nejmra1314530 PMID: 25539106

11. Mchembe MD, Rambau PF, Chalya PL, Jaka H, Koy M, Mahalu W. Endoscopic and clinicopathological patterns of esophageal cancer in Tanzania: experiences from two tertiary health institutions. World J Surg Oncol. 2013;11(1):257 Available from: http://dx.doi.org/10.1186/1477-7819-11-257 PMID: 24094270

12. Solanke TF. Carcinoma of the esophagus in Ibadan. Int Surg. 1969 Sep;52(3):204. PMID: 5804091

13. Ali A, Ersumo T, Johnson O. Oesophageal carcinoma in TikurAnbessa Hospital, Addis Ababa. East Afr Med J. 1998 Oct;75(10):590-3. PMID: 10065194

14. Patel K, Wakhisi J, Mining S, Mwangi A, Patel R. Esophageal Cancer, the Topmost Cancer at MTRH in the Rift Valley, Kenya, and Its Potential Risk Factors. ISRN Oncology. 2013;2013:1-9. Available from: http://dx.doi.org/10.1155/2013/503249 PMID: 24490085

15. Walker AR, Walker BF, Isaacson C, Segal I, Pryor S. Short duration of survival among South African blacks with oesophageal cancer. S Afr Med J. 1984 Dec;66(23):877-8. PMID: 6505894

16. Kneebone RL, Mannell AY. Cancer of the oesophagus in Soweto. S Afr Med J. 1985 May;67(21):839-42. PMID: 3992421

17. Mannell A, Murray W. Oesophageal cancer in South Africa. A review of 1926 cases. Cancer. 1989 Dec 15;64(12):2604-8. PMID: 2819670

18. Ajani JA, Barthel JS, Bentrem DJ, D'Amico TA, Das P, Denlinger CS, et al. Esophageal and esophagogastric junction cancers. J Natl Compr Canc Netw. 2011 Aug 1;9(8):830-87. PMID: 21900218

19. Dai Y, Li C, Xie Y, Liu X, Zhang J, Zhou J, et al. Interventions for dysphagia in oesophageal cancer. Cochrane Database Syst Rev. 2014 Oct 30. Available from: http://dx.doi org/10.1002/14651858.cd005048.pub4 PMID: 25354795

20. Govender M, Aldous C, Ferndale L, Thomson SR, Clarke DL. Self-expanding metal stent placement for oesophageal cancer without fluoroscopy is safe and effective. S Afr Med J. 2015 Sep 19;105(10):858. Available from: http://dx.doi.org/10.7196/ samjnew.8329 PMID: 26428593

21. Sabharwal T. A randomised prospective comparison of the Flamingo Wallstent and Ultraflex stent for palliation of dysphagia associated with lower third oesophageal carcinoma. Gut. BMJ; 2003 Jul 1;52(7):922-6. Available from: http:// dx.doi.org/10.1136/gut.52.7.922 PMID: 12801944

22. Watkinson AF, Ellul J, Entwisle K, Mason RC, Adam A. Esophageal carcinoma: initial results of palliative treatment with covered self-expanding endoprostheses. Radiology. 1995 Jun;195(3):821-7. Available from: http://dx.doi.org/10.1148/ radiology.195.3.7538682 PMID: 7538682

23. Gray RT, O’Donnell ME, Scott RD, McGuigan JA, Mainie I. Self-expanding metal stent insertion for inoperable esophageal carcinoma in Belfast: an audit of outcomes and literature review. Dis Esophagus. 2011 Mar 18;24(8):569-74. Available from: http://dx.doi.org/10.1111/j.1442-2050.2011.01188.x PMID: 21418125

24. Burstow M, Kelly T, Panchani S, Khan IM, Meek D, Memon B, et al. Outcome of palliative esophageal stenting for malignant dysphagia: a retrospective analysis. Dis Esophagus. 2009 Sep;22(6):519-25. Available from: http://dx.doi.org/10.1111/ j.1442-2050.2009.00948.x PMID: 19302213

25. Homs MY, Steyerberg EW, Eijkenboom WM, Tilanus HW, Stalpers LJ, Bartelsman JF, et al. Single-dose brachytherapy versus metal stent placement for the palliation of dysphagia from oesophageal cancer: multicentre randomised trial. Lancet. 2004 Oct;364(9444):1497-504. Available from: http://dx.doi. org/10.1016/s0140-6736(04)17272-3 PMID: 15500894

26. Steyerberg EW, Homs MYV, Stokvis A, Essink-Bot M-L, Siersema PD. Stent placement or brachytherapy for palliation of dysphagia from esophageal cancer: a prognostic model to guide treatment selection. Gastrointest Endosc. 2005 Sep;62(3):333-40. Available from: http://dx.doi.org/10.1016/ s0016-5107(05)01587-7 PMID: 16111947

27. Bergquist $H$, Wenger U, Johnsson E, Nyman J, Ejnell $\mathrm{H}$, Hammerlid E, et al. Stent insertion or endoluminal brachytherapy as palliation of patients with advanced cancer of the esophagus and gastroesophageal junction. Results of a randomized, controlled clinical trial. Dis Esophagus. 2005 Aug 1;18(3):131-9. Available from: http://dx.doi.org/10.1111/j.14422050.2005.00467.x PMID: 16045572

28. Caspers RJL, Welvaart K, Verkes RJ, Hermans J, Leer JWH. The effect of radiotherapy on dysphagia and survival in patients with esophageal cancer. Radiother Oncol. 1988 May;12(1):1523. Available from: http://dx.doi.org/10.1016/01678140(88)90188-0 PMID: 2457230

29. Cwikiel M, Cwikiel W, Albertsson M. Palliation of Dysphagia in Patients with Malignant Esophageal Strictures: Comparison of results of radiotherapy, chemotherapy and esophageal stent treatment. Acta Oncol. 1996 Jan;35(1):75-9. Available from: http://dx.doi.org/10.3109/02841869609098483 PMID: 8619944

30. Moses FM, Peura DA, Wong RKH, Johnson LF. Palliative dilation of esophageal carcinoma. Gastrointest Endosc. 1985 Apr;31(2):61-3. Available from: http://dx.doi.org/10.1016/ s0016-5107(85)71993-1 PMID: 2581846

31. Heit HA. Palliative Dilation for Dysphagia in Esophageal Carcinoma. Ann Intern Med. 1978 Nov 1;89(5 Part 1):629. Available from: http://dx.doi.org/10.7326/0003-4819-89-5-629 PMID: 82417

32. Aste H, Munizzi F, Martines H, Pugliese V. Esophageal dilation in malignant dysphagia. Cancer. 1985 Dec 1;56(11):2713-5. PMID: 2413980

33. Lundell L, Leth R, Lind T, Lönroth H, Sjövall M, Olbe L. Palliative endoscopic dilatation in carcinoma of the esophagus and esophagogastric junction. Acta Chir Scand. 1989 Mar;155(3):179-84. PMID: 2472723

34. Allum WH, Griffin SM, Watson A, Colin-Jones D. Guidelines for the management of oesophageal and gastric cancer. Gut. BMJ; 2002 Jun 1;50(Supplement 5):v1-v23. Available from: http://dx.doi.org/10.1136/gut.50.suppl_5.v1 PMID: 12049068

35. Allum WH, Blazeby JM, Griffin SM, Cunningham D, Jankowski JA, Wong R, et al. Guidelines for the management of oesophageal and gastric cancer. Gut. BMJ; 2011 Jun 24;60(11):1449-72. Available from: http://dx.doi.org/10.1136/ gut.2010.228254 PMID: 21705456

36. Benatar SR. The challenges of health disparities in South Africa. S Afr Med J. 2013 Jan 23;103(3):154. Available from: http://dx.doi.org/10.7196/samj.6622 PMID: 23472690

37. Mayosi BM, Benatar SR. Health and Health Care in South Africa - 20 Years after Mandela. N Engl J Med; 2014 Oct 2;371(14):1344-53. Available from: http://dx.doi.org/10.1056/ nejmsr1405012 PMID: 25265493

38. Death and dying in the Eastern Cape: an investigation into the collapse of a health system. Treatment Action Campaign and Section27 Catalysts for Social Justice, 2013. Available from: http://www.hst.org.za/publications/death-and-dying-easterncape-investigation-collapse-health-system

39. Govender M, Ferndale L, Clark DL. Oesophageal cancer in South Africa: The long timeline from onset of symptoms to definitive management. S Afr J Oncol. 2017 May 26;1:3. Available from: http://dx.doi.org/10.4102/sajo.v1i0.6

40. Dandara C, Robertson B, Dzobo K, Moodley L, Parker MI. Patient and tumour characteristics as prognostic markers for oesophageal cancer: a retrospective analysis of a cohort of patients at Groote Schuur Hospital. Eur J Cardiothorac Surg. 2015 Apr 12;49(2):629-34. Available from: http://dx.doi. org/10.1093/ejcts/ezv135 PMID: 25870217 